\title{
"O TRABALHO NA FORMA DE ALEGRIAJUVENIL": A GINÁSTICA SEGUNDO JOHANN CHRISTOPH FRIEDRICH GUTS MUTHS'
}

\author{
MS. EVELISE AMGARTEN QUITZAU \\ Mestre em Educação Física - Universidade Estadual de Campinas \\ Aluna do Programa de Pós-Graduação em Educação - Universidade Estadual de Campinas \\ (Campinas - São Paulo - Brasil) \\ E-mail: eveliseaq@yahoo.com.br
}

\begin{abstract}
RESUMO
Este trabalho tem como objetivo estabelecer uma aproximação com a obra de Johann Christoph Friedrich Guts Muths, pedagogo alemão que, no final do século XVIII, publicou uma das obras fundamentadoras da ginástica alemã: Gymnastik für die Jugend (Ginástica para a Juventude). Seu trabalho baseia-se principalmente nas teorias da denominada polícia médica, e apresenta um forte discurso em defesa da instituição dos exercícios físicos como instrumento de regeneração e fortalecimento da população alemã.
\end{abstract}

PALAVRAS-CHAVE: História da ginástica; Alemanha; Guts Muths; educação do corpo.

I. O presente trabalho é parte de pesquisa de mestrado realizada na Faculdade de Educação Física da Unicamp, com apoio financeiro da FAPESP, processo número 2009/02043-3. 
A passagem do século XVIII para o XIX marca um período de mudanças na Europa. Em meio a guerras, crises sociais e revoluções, observa-se uma efervescência cultural, o advento de novas teorias filosóficas, descobertas científicas e, consequentemente, novas formas de se olhar para o corpo. É neste ambiente que começam a se desenvolver as primeiras sistematizações dos exercícios físicos que originaram o que hoje conhecemos como Educação Física.

Neste período, observa-se na Alemanha² a consolidação das práticas administrativas baseadas no cameralismo, ciência política que começou a se desenvolver ainda no século XVII, e que partia da premissa de que o bem-estar do Estado estava intimamente ligado ao bem-estar da sociedade. Esse conjunto de ideias e práticas de governo, que buscava ter, sempre, o maior conhecimento possível sobre o funcionamento do Estado para a execução de um governo apropriado, apresenta os cuidados com saúde da população como uma das preocupações básicas do Estado, levando à concepção de uma ciência conhecida como polícia médica.

A polícia médica consistia num sistema de observação dos níveis de morbidade, epidemias e endemias, da padronização da prática e dos conhecimentos médicos, da organização para controlar os médicos e da criação de funcionários responsáveis por determinadas regiões do território. À primeira vista, a ideia de desenvolvimento de um sistema centralizador da saúde pública tão organizado, em território alemão, pode soar estranha, dada a total fragmentação política germânica. Todavia, segundo Foucault (2008), foi exatamente esta divisão territorial que levou a uma superproblematização das questões da polícia ${ }^{3}$ na Alemanha no século XVIII. Segundo o autor, a fragmentação territorial e as diversas reorganizações pelas quais passaram após o tratado de Vestfália, fizeram com que os estados alemães, intermediários entre a estrutura feudal e os grandes Estados, se tornassem "espaços privilegiados de experimentação estatal” (FOUCAULT, 2008, p. 426). A necessidade de um corpo burocrático capacitado para tais experimentações, por sua vez, levou à criação de numerosas cadeiras de "ciência da polícia" em universidades por todo o território alemão, de onde saíram inúmeras teses e manuais que se difundiram pela Europa.

Ao mesmo tempo em que o corpo passa a ser visto como peça-chave para o desenvolvimento do Estado, também passa a ser visto como elemento fundamental na educação da população. Na Alemanha, a maior influência para se

2. É importante ressaltar que, no período trabalhado, a Alemanha ainda não se constituía como um Estado unificado, mas como um conglomerado de principados autônomos unidos sob a égide do Sacro Império Romano Germânico.

3. É importante termos em mente que, ao falarmos em polícia, neste período, nos referimos ao "conjunto dos meios pelos quais é possível fazer as forças do Estado crescerem, mantendo ao mesmo tempo a boa ordem desse Estado" (FOUCAULT, 2008, p. 42I). 
pensar as relações entre corpo e educação é a obra O Emílio, escrita por Rousseau em 1762, na qual se defende fortemente que a educação das crianças seja feita em meio à natureza, ao ar livre, onde elas possam mover-se livremente, utilizando vestimentas confortáveis, trabalhando simultaneamente mente e corpo. É essa obra que influencia a fundação, em 1774, na cidade de Dessau, do Philantropinum, escola onde foram dados os primeiros passos na direção de uma sistematização dos exercícios físicos, ainda no final do século XVIII. Seu criador, o pedagogo Johann Bernhard Basedow (1724- 1790), amparado nas ideias de Rousseau, busca elaborar um currículo que possibilitasse um equilíbrio entre educação intelectual e física. Neste sentido, propõe uma rotina diária composta por 5 horas de estudos, 2 horas de trabalhos manuais e 3 horas de recreação, período no qual os alunos eram guiados na prática de atividades como equitação, esgrima, dança e música. No verão, eram recomendadas incursões ao campo, onde os alunos teriam a oportunidade de pescar, remar, caçar, pular e escalar, bem como de estudar as ciências naturais de forma aprofundada. Este trabalho realizado por Basedow , embora não tenha resistido por muito tempo, lançou as bases para a constituição de outras escolas nos mesmos moldes, entre elas o Philantropinum de Schnepfenthal, influenciando o trabalho de Johann Christoph Friedrich Guts Muths, autor daquele que seria considerado o primeiro manual de ginástica publicado na Alemanha: Gymnastik für die Jugend ${ }^{4}$ (Ginástica para a Juventude).

\section{A GINÁSTICA PARA A JUVENTUDE}

Nascido na pequena cidade prussiana de Quedlingburg, em agosto de 1759 , Guts Muths cresceu lendo em meio a trabalhos manuais e a livros, dentre os quais se destacava a chamada "Acerra Philologica", um conjunto de textos selecionados de célebres autores da Antiguidade, traduzidos para o alemão, e que, segundo Leonard ( 1927), muito provavelmente deve ter-lhe introduzido a ginástica praticada por gregos e romanos.

Em 1779, Guts Muths entrou para a Universidade de Halle, onde estudou teologia e frequentou cursos de matemática, física, línguas modernas (inglês e italiano) e pedagogia, cujo interesse vinha desde o fim de seu curso ginasial, quando entrou em contato com as obras "Elementarwerk" ( 1774) e "Methodenbuch" ( 1770), publicadas por Basedow. Após três anos em Halle, retorna à sua cidade natal e,

4. Para a elaboração deste trabalho, utilizo a tradução inglesa da obra, publicada em $\mid 800$. 
em 1784, muda-se para Schnepfenthal, onde passa a trabalhar como professor de geografia e francês, entre outras eventuais disciplinas básicas, no Philantropinum criado por Christian Gotthilf Salzmann. ${ }^{5}$

A ginástica passou aos seus cuidados apenas em 1786. Como responsável pela educação corporal dos alunos de Schnepfenthal, Guts Muths frequentemente os levava para exercícios de marcha, de equilíbrio, saltos diversificados, arremessos e trabalhos manuais, sempre executados ao ar livre. É a partir da experiência adquirida com tais práticas que, em 1793, publica o livro Gymnastik für die Jugend, ou Ginástica para a Juventude.

Há algumas características que podem ser apontadas, com relação à argumentação feita por Guts Muths para explicitar a importância da ginástica. A saúde, como apontado por Tesche (2002), é peça fundamental de sua obra, bem como atributos da destreza e da capacidade física, defendidos a partir das teorias da polícia médica. ${ }^{6}$ Além da medicina, obras de pensadores do período, como Locke e, principalmente, Rousseau, são base para a defesa não apenas da inserção dos exercícios físicos no cotidiano da juventude, mas também de um retorno à natureza, combatendo os males decorrentes da vida urbana e inativa.

Logo no prefácio de seu livro, Guts Muths deixa claro quais deveriam ser as bases para uma boa teoria da ginástica, ao afirmar estar

[... ciente de que uma verdadeira teoria da ginástica deveria ser elaborada baseada em princípios fisiológicos, e a prática de cada exercício regulada pelas qualidades físicas de cada indivíduo, mas tal perfeição não é esperada deste trabalho, feito somente pela genuína experiência de 8 anos de prática, que me convenceram que a ginástica é necessária à educação... (GUTS MUTHS, 1800, p.viii).

Esse trecho ilustra bem a importância dos princípios biológicos para a sistematização dos exercícios físicos em sua obra. Entretanto, o próprio autor indica uma "imperfeição" em seu livro, ao dizer que ele é feito baseado apenas em seus anos de prática em Schnepfenthal. Tal "imperfeição" é justificada, alguns parágrafos mais adiante, quando indica que "requerer um tratado de ginástica, portanto, baseado na anatomia e fisiologia, seria inconsistente com as presentes circunstâncias" (GUTS

5. Christian Gotthilf Salzmann (|744-|8| I), fundador do Philantropinum de Schnepfenthal, escola inspirada no Philantropinum de Dessau.

6. A polícia médica consistia num sistema de observação dos níveis de morbidade, epidemias e endemias, da padronização da prática e dos conhecimentos médicos, da organização para controlar os médicos e da criação de funcionários responsáveis por determinadas regiões do território. Durante o século XVIII, diversas obras sobre o tema são publicadas na Alemanha. (FOUCAULT, 2008; ROSEN, 1980) 
MUTHS, I800, p. ix), em que as pessoas encarregadas da educação da juventude são muito mais engajadas no estudo do divino do que no estudo das questões médicas. Dessa forma, "a mais perfeita performance teórica é de pouca utilidade, se não for adaptada ao local e às circunstâncias, o que de fato acontece com um sistema ginástico puramente fisiológico". (GUTS MUTHS, I800, p. ix).

Uma ideia muito presente na obra de Guts Muths é a de que a degenerescência física pela qual passava a população alemã, ao contrário do que apontavam outros intelectuais, não era fruto de uma "inatividade da natureza", mas de uma sociedade inativa; era culpa dos próprios indivíduos se a juventude não atingia os níveis de saúde possíveis e desejáveis para a sociedade. Sob seu ponto de vista, os antigos alemães eram colocados desde cedo em contato com a natureza. Quando bebês eram envoltos com roupas leves, e levados para banhos nos riachos, o que possibilitava, desde cedo, o fortalecimento do corpo. Tinham uma dieta simples, e quando cresciam, eram introduzidos por seus pais aos exercícios militares, à caça, à equitação. Conclui que o movimento e o trabalho abundante em meio ao ar livre, bem como uma dieta simples e roupas leves, era o que dava a esses alemães de outrora, saúde, força, agilidade, firmeza do corpo, coragem, sinceridade.?

Ao analisar o modo como se dá a educação das crianças em seu tempo, percebe que nenhum destes elementos está presente. Se antes elas eram banhadas em riachos e cobertas com roupas leves, agora tomavam banhos mornos e ficavam enfaixadas em roupas que thes impediam quaisquer movimentos dos membros, e seu corpo permanecia "imerso num banho de vapor composto por suas próprias exalações" (GUTS MUTHS, I800, p. 5). A situação da criança não muda muito quando cresce: ainda privada de movimentos livres, passa o dia trancafiada dentro de casa, onde dorme em camas quentes, tem refeições requintadas e toma remédios como medida profilática buscando preservar sua saúde.

Se as crianças de antigamente estavam em constante contato com a natureza e aprendiam tudo o que ela tinha a ensinar, as crianças do final do século XVIII não tinham essa chance. Não por falta de vontade própria, mas pela falta de incentivo, tanto da família quanto dos governantes, que não tomavam medidas para encorajar a prática de exercícios físicos ao ar livre. Neste modelo de educação, formulado para estimular a formação da mente, o corpo encontrava-se completamente

7. Segundo Thomas (200I), no final do século XVIII, a admiração pela natureza convertera-se numa devoção quase religiosa. O meio natural, as florestas, passam a ser vistas como um local moralmente benéfico, que propiciava um "lugar de privacidade, uma oportunidade de auto-exame e de devaneio íntimo; tinha um papel mais positivo: exercia um salutar poder espiritual sobre os homens" (GUTS MUTHS, I800, p. 309). 
negligenciado. Nas escolas não havia espaço para a educação física, pois isto não fazia parte de seus planos. Observa-se, portanto, que Guts Muths vai ao encontro das mudanças em relação à educação das crianças que marcam o final do século XVIII. Segundo Donzelot (1986), neste momento o pensamento social e médico volta-se contra a criadagem e as práticas de confinamento das crianças dentre as quais se destaca o hábito de enfaixá-las por completo , buscando suprimir as falhas da educação privada recebida na primeira infância que, futuramente, poderiam se traduzir em hábitos viciosos e numa vida imoral, ações que feririam diretamente a integridade da sociedade e do Estado.

Algumas atividades, todavia, são inseridas na vida destas crianças. Segundo Guts Muths (1 800), nas famílias de classes mais altas, assim que a criança atinge seus dez ou doze anos, é introduzida a um professor de dança, que the ensina a deslizar por um salão — o que não traria benefício algum à sua saúde corporal —, ou à esgrima, esta sim uma atividade digna de atenção por desenvolver a força corporal e a coragem. Estas, entretanto, são possibilidades exclusivas das classes mais abastadas. Numa Alemanha em que a maioria dos indivíduos ainda vivia no meio rural, com péssimas condições de vida e uma alimentação muito pobre, muitas crianças acabavam adentrando o mundo do trabalho precocemente, e essa situação não passa despercebida pelo pedagogo, que afirma que

[... ] as crianças das classes mais pobres são colocadas para trabalhar, para ganhar seu pão, assim que atingem os 10 ou 12 anos. Frequentemente são forçadas a fazer, sob a dor da correção, as tarefas dos adultos. Isso é horrível: todavia é verdade. A pouca instrução da mente raramente alcançou um décimo, e o corpo talvez tenha alcançado metade de seu crescimento, quando o pobre menino é tirado da escola e condenado ao trabalho escravo, para o bem de seu estômago. Nós poupamos o potro forte; não colocamos muito cedo a armadura ou a sela; mas as crianças pobres não são poupadas, não são dispensadas do trabalho pesado. Toda a juventude sofre sob esse fardo que lhes é imposto tão cedo: muitos, ao invés de crescer com vigor, têm seu desenvolvimento impedido, adquirem defeito corporal ou destroem para sempre a elasticidade de seus músculos, enquanto suas articulações endurecem na rigidez. Enquanto temos pena do jovem potro, devemos fechar nossos olhos para a miséria à qual nossos pequenos são expostos? Nenhum Estado deveria permitir isso: certamente é possível que uma nação floresça sem deliberadamente ferir tantos membros (GUTS MUTHS, I800, p. I6- I7).

Assim, a debilidade corporal do homem civilizado não poderia ser vista como uma suposta falha ou inatividade da natureza. Tal como para Rousseau, constante referência em Ginástica para a Juventude, para Guts Muths a natureza formaria todas as criaturas com o mesmo poder, as mesmas forças, tanto em seu tempo, quanto num período anterior. $O$ declínio das forças e da saúde da sociedade alemã no final 
do século XVIII não poderia, portanto, ser creditado a nada além do modo de vida da população, de uma "educação não natural", que negligenciava uma educação do corpo, confundindo a "saúde e força física com ferocidade" (GUTS MUTHS, I800, p. I); isso somente seria verdade se tais atributos fossem cultivados em desarmonia com a mente: um depende diretamente do outro.

O sistema de educação vigente no período (fins do século XVIII, início do XIX) é visto por este pedagogo como o grande responsável pela inatividade corporal, pelas doenças e inúmeros outros sofrimentos, uma vez que desobedece as leis da natureza, rejeitando em seus planos o aperfeiçoamento das faculdades corporais a partir dos exercícios físicos e formando, portanto, homens de muito conhecimento, porém de corpo fragilizado, indo contra a orientação de que a educação deveria formar "um corpo forte e uma mente forte" (GUTS MUTHS, I800, p. 55). Como consequência dessa educação que negligencia o corpo, observa-se, então, a formação de indivíduos fracos, sem destreza, enfermos, inativos, que não sabem escolher seus divertimentos, e cuja mente é debilitada. Um dos principais objetivos da educação ginástica seria, portanto, estimular os jovens a exercitar seu corpo fugindo, assim, de uma debilidade física e mental. Para fazer valer seus argumentos, Guts Muths utilizava a própria natureza, conforme podemos observar na seguinte passagem:

destrua as raízes das plantas mais saudáveis que elas inclinarão e morrerão. Muitas excelentes qualidades da mente têm suas raízes, na verdade, no corpo. Os vértices que adornam o ser espiritual, a mente, definharão se negligenciarmos o solo destas plantas valiosas e, assim, machucarmos suas raízes (GUTS MUTHS, I800, p.8I-82).

Embora reconheça que algumas mudanças nos modos de educação começaram a acontecer entre as classes mais altas, especialmente influenciadas pelo trabalho de Basedow, afirma que uma reforma ainda se faz necessária com relação à educação física, fato que já fora reconhecido também pelos médicos e professores. O preconceito, contudo, ainda é o maior obstáculo para isso e, mesmo o trabalho de Basedow em Dessau, é apontado por Guts Muths como uma reforma em nome da formação intelectual, continuando a negligenciar as questões relacionadas à educação do corpo (GUTS MUTHS, I800, p.89).

Entre todos estes fatores apontados como estimuladores da degenerescência física na população, Guts Muths encontra o que considera "causas acidentais", que contribuiriam para retardar o declínio das capacidades corporais da população. Uma é a suposta propensão natural das crianças de brincarem ao ar livre, compensando, assim, os erros cometidos pela educação escolar. Outra causa considerada importante para o retardo da degenerescência física da população são as ocupações ao ar 
livre, em que os jovens começam a se engajar por volta dos treze anos. Há, todavia, uma ressalva com relação a esta segunda situação: se por um lado ela possibilita o fortalecimento corporal destes jovens, muitas vezes estes são obrigados a realizar tarefas além de suas capacidades.

A resposta encontrada por Guts Muths para reverter os problemas deste modo de vida e educação que ele chama de corrupto, é a ginástica: a religião e a moral de nada adiantam quando se luta contra a fraqueza corporal, contra a inatividade, e todas as consequências dela decorrentes. $\bigcirc$ fortalecimento do corpo garante a estabilidade e firmeza dos nervos: logo, revigoram a mente, que se torna mais "enérgica, infatigável, firme e corajosa; serenidade será difundida por ela, que será ativa como a natureza" (GUTS MUTHS, 1800, p. I02).

Dirigindo-se aos tutores, mestres de escola, aos príncipes e à nação, Guts Muths evoca o nome de dois povos para exemplificar a importância dos exercícios físicos: os romanos e, principalmente, os gregos. Lamenta que, embora muitos tenham se baseado nos preceitos desses povos no que diz respeito à formação da mente, ninguém atentou às suas práticas para a formação do corpo, cujos objetivos, segundo ele, eram a "robustez, força e destreza do corpo, elegância da forma, coragem, presença de espírito no perigo e patriotismo formado a partir destes" (GUTS MUTHS, I800, p. I05). Admira o fato de que professores eram pagos pelo estado para cuidar da educação do corpo, bem como os edifícios erigidos para as práticas corporais, os festivais e jogos. Estes eram vistos pelo pedagogo alemão como uma forma de "apoiar o espírito nacional, preservar os jovens cidadãos da efeminação, inspirá-los nos sentimentos varonis e formá-los heróis"8 (GUTS MUTHS, I800, p. I I2).

Ao se questionar sobre o que impediria os alemães de "imitar" estas práticas comuns entre os gregos, Guts Muths aponta alguns obstáculos e objeções impostos contra a ginástica, que seriam: a falta de locais apropriados, como os gregos; a escassez de professores; a escassez de tempo; a ridicularização da execução de movimentos próprios da ginástica; o perigo; a alienação dos trabalhos sedentários; rudeza da mente; e a formação de uma autoconfiança que poderia se tornar peri-

8. Observa-se, aqui, uma aproximação de Guts Muths a certas teorias de Schelling relacionadas à Naturphilosophie (termo utilizado no final do século XVIII para designar a busca de superação da visão mecanicista do mundo a partir de paralelos entre medicina e física). Para este filósofo, a natureza era um sistema orgânico em cujo cerne desdobrava-se uma luta polarizada entre a luz e a noite, posteriormente identificados, respectivamente, como o masculino (elemento ideal da natureza) e o feminino (elemento real). Conforme Schelling, se a Antiguidade fora "governada pela amizade e pelas virtudes viris, exercitada às livres luzes da polis" (WILLIAMSON, 2004, p. 64), a sociedade em que vivia, a "modernidade cristã", assistia a privatização e efeminação, instigadas através dos romances cavalheirescos medievais, cujo eixo era a busca do amor feminino e da felicidade doméstica, ou seja, privada. 
gosa. Cada um destes obstáculos é desconstruído em Ginástica para a Juventude, buscando mostrar que é possível introduzir a ginástica na educação dos jovens.

Para ele, não é necessário erigir prédios específicos para a prática da ginástica como os gregos, uma vez que os exercícios, bem como os possíveis aparelhos a serem usados, são simples; os pais das crianças não se negariam a contribuir com valores pequenos para a implementação de aparelhos de ginástica nas escolas, se esta fosse uma prática valorizada por seus diretores e pelos governantes, e se estes defendessem os exercícios e enaltecessem os festivais nacionais que, sob sua ótica, eram uma poderosa forma de agir pela formação de um espírito nacional, inspirando e guiando os indivíduos ao patriotismo, à virtude e à honra (GUTS MUTHS, I800, p. I5).

Da mesma forma que rebate o primeiro obstáculo, se dedica a contra-argumentar cada uma das objeções encontradas contra a inserção da ginástica na educação. Sobre a escassez de professores, citando Frank, ${ }^{9}$ afirma que cada escola deveria ter um mestre de ginástica; sobre a escassez de tempo, baseia-se novamente em Rousseau, ao afirmar que o exercício do corpo e da mente deve servir de relaxamento um para o outro, e indica um maior controle sobre o tempo de sono, jogos de cartas, teatros e alimentação dos jovens, reduzindo-se o número de horas inativas e aumentando-se o tempo que passam exercitando o corpo. Citando Tissot, ${ }^{10}$ afirma que

[... não há, talvez, maior e mais repreensivo erro na educação, do que a cruel propensão de compelir as crianças a extraordinários esforços (mentais) e exigir um rápido progresso: isso é o túmulo tanto para sua saúde quanto para seu talento; e, não obstante tudo o que tem sido dito contra isso por homens de grandes habilidades, que atacam com cada vez mais força do que sucesso, é algo muito comum (GUTS MUTHS, I800, p. I 22, grifos do autor).

Dentre as objeções apontadas, talvez a que mais chame a atenção é a suposta formação de uma autoconfiança que poderia se tornar perigosa. Segundo Guts Muths, os indivíduos contrários à ginástica acreditam que a autoconfiança gerada pela prática de exercícios físicos daria ao indivíduo uma propensão a ser seu próprio socorro, algo considerado perigoso e inútil aos cidadãos pacíficos. Contudo, para ele, a autoconfiança é bem-vinda: ela somente se tornará um perigo se o desenvolvimento das forças corporais não for acompanhado do desenvolvimento da mente.

9. Johann Peter Frank ( 1745 - | 82 I ), médico alemão, autor de System einer vollständigen medicinischen Polizey ( 1779) — Sistema de polícia médica —, obra considerada por Rosen (1980) como um marco da polícia médica.

10. Samuel Auguste André David Tissot (1728- 1797), médico suíço. 
Após extensa revisão sobre a degenerescência física e os modos de educação da população, Guts Muths conclui que o homem deve ser o mais educado possível, sua rudeza deve ser lapidada, mas ele nunca deve tornar-se refinado. Para ele, há um grande problema conceitual que leva à equivalência dos termos educação e refinamento, sendo crucial, portanto, distingui-los. Enquanto o refinamento é visto como um "aumento da sensualidade pela indulgência" (GUTS MUTHS, I800, p. 139), a educação é a "melhoria corporal e intelectual do homem" (GUTS MUTHS, I800, p. | 39-140). A educação fortalece todos os poderes; o refinamento os enfraquece. Portanto, "a melhor educação leva à melhor capacidade de suportar as alegrias e tristezas da vida" (GUTS MUTHS, 1800, p. 84).

A análise dos modos de educação e o levantamento deste "erro conceitual" levam Guts Muths a concluir que a educação física dos alemães é muito impotente, se comparada à intelectual. A ginástica é vista como o caminho para a construção do cidadão perfeito, tendo como único objetivo a harmonia entre corpo e mente (GUTS MUTHS, I 800, p. I 43). Todavia, não deve ser buscada sozinha, substituindo a educação da mente: isso simplesmente formaria um selvagem. Assim, "o grande segredo da educação consiste em fazer com que os exercícios do corpo e os do espírito sirvam mutuamente de distração" (GUTS MUTHS, 1800, p. I 45; ROUSSEAU, 1968, p.224).

A partir da ginástica, deseja-se, então, formar um homem cujo corpo é saudável e a mente serena. Busca-se, através dos exercícios ginásticos, aumentar a saúde, não destruí-la; pretende-se formar um sujeito corajoso, não um feroz selvagem.

\section{UM MANUAL DE GINÁSTICA}

Se fosse necessário dar uma definição aos exercícios ginásticos, este autor diria que a "ginástica é o trabalho na forma de alegria juvenil" (GUTS MUTHS, 1800 , p. 187). Este trabalho deveria promover a circulação e o fortalecimento dos músculos e nervos, devendo às vezes colocar o corpo inteiro em movimento, às vezes apenas algumas partes, mas nunca sobrecarregando o organismo com exercícios excessivos. Deveria agir como prevenção contra a sensualidade efeminada e forjar tanto o homem físico quanto o moral. Por isso, a ginástica deveria

\footnotetext{
requerer paciência e perseverança; não admitir o sono debilitante; habituar o aluno a mais ou menos dor, a qual ele deve aprender a conter; e expô-lo ao clima e aos elementos para enrijecer seus tegumentos, que são projetados para proteger todo o corpo (GUTS MUTHS, 1800, p. 188).
}

Os exercícios ginásticos aplicáveis aos propósitos da educação defendidos por Guts Muths podem ser divididos em três classes, denominadas exercícios ginásticos 
propriamente ditos, trabalhos manuais e jogos sociais para a juventude. " Define, então, um sistema de ginástica organizado de forma "genérica", em que os exercícios são agrupados segundo seu tipo, não segundo seus benefícios ou princípios anatômicos. Guts Muths traz em seu livro indicações para o trabalho do saltar, correr, arremessar, lutar, escalar, equilibrar, levantar e carregar, pular corda/arco, dançar, andar, exercícios militares, banhar-se, nadar, exercícios aleatórios, declamação, exercício dos sentidos e trabalhos manuais. ${ }^{12}$

$\mathrm{Na}$ estruturação de seu manual, entre várias proposições, encontra-se a descrição do exercício de escalar, visto por Guts Muths como ótimo para adquirir vigor e força muscular, fortalecer mãos e pernas, preparar o aluno para ficar em locais altos sempre que necessário e sem sentir vertigem, tornando-o mais corajoso e preparado para enfrentar situações de perigo. Tal qual acontecia com os diferentes tipos de saltos, a escalada também era precedida por uma série de exercícios preparatórios, que tinham como principal objetivo, neste caso, fortalecer braços e pernas para a manutenção do corpo no percurso da escalada. Um exemplo de tais exercícios preparatórios era manter o corpo suspenso pelo maior tempo possível, apenas segurando-se com as mãos no aparelho. Para aumentar a dificuldade, o mestre poderia propor, caso a habilidade dos alunos já permitisse, que utilizassem apenas uma das mãos para manterem-se pendurados. Para o exercício dos membros inferiores, propunha-se que os alunos sustentassem o corpo a uma determinada altura em um mastro, utilizando apenas os pés e pernas para manter-se apoiado. Somente após os alunos terem dominado estes exercícios, eles poderiam passar para a escalada propriamente dita. Tais variações eram vistas por Guts Muths não apenas como uma forma de alterar-se o grau de dificuldade de determinada tarefa, mas também como um fator motivador, para impedir que as atividades se tornassem "monótonas" e garantir que seus alunos continuassem a querer praticá-las e a divertir-se durante as aulas.

Para a execução da escalada era proposto um aparelho próprio, composto por um mastro, uma corda e uma escada de corda. $\bigcirc$ autor traz as especificidades de cada uma dessas partes, indicando a melhor forma de utilizá-las, bem como

II. Sobre este assunto, Guts Muths fala mais especificamente no livro "Jogos para o Exercício e a Recuperação do Corpo e do Espírito, para os Jovens, seus Educadores e todos os companheiros da inocente alegria juvenil" — Spiele zur Übung und Erholung des Körpers und Geistes, für die Jugend, ihre Erzieher und alle Freunde unschuldiger Jugendfreuden (1796). Nesta obra, o autor traz diversos jogos divididos em duas classes — "de movimento" e "tranquilos".

12. Sobre os trabalhos manuais, Guts Muths afirma que o jovem deve aprender pequenos ofícios, como a jardinagem e a carpintaria, juntamente com o estudo das ciências, especialmente da mecânica. Para o autor, é possível esperar grandes feitos de uma nação cuja população, além de apresentar aptidão para as invenções e um espírito perseverante, também possui um bom conhecimento teórico e prático da mecânica (GUTS MUTHS, 1800, p. 429). 
dificuldades e benefícios de cada uma. Traz também precauções que devem ser tomadas no que diz respeito aos materiais a serem utilizados na construção do aparelho, bem como com relação à execução dos exercícios. E, também como ocorre com os saltos, traz variações e situações-problema para os alunos, fazendo com que busquem, desde os exercícios preparatórios para a escalada, formas de resolverem a questão proposta pelo professor.

Esta mesma estrutura pode ser observada em todos os grupos de exercícios apresentados por Guts Muths. Sobre o correr, por exemplo, também o divide em categorias e aponta-o como uma das mais importantes da natureza para a preservação da vida. Afirma, citando Frank, que "assim que as jovens crianças se tornam excelentes no andar, desviar e semelhantes, as corridas, com as devidas precauções, são excelente exercício para eles" (GUTS MUTHS, I800, p. 227). Este excelente exercício tem como benefícios o fortalecimento dos membros inferiores e dos pulmões e deveria ser praticado, quando na forma de corridas longas, no inverno, "quando o ar é puro e fortificante, e o frio excita a velocidade dos movimentos" (GUTS MUTHS, I 800, p. 232).

Alguns aspectos de outros exercícios merecem atenção especial. A luta, por exemplo, é vista por ele como um excelente exercício ginástico que foi degenerado a partir do momento em que se transformou em competições brutais. Sobre o equilíbrio, traz variados exercícios, tanto equilibrando o próprio corpo em aparelhos, quanto equilibrando objetos no corpo, e defende a prática da funambulação, apontado-a como um excelente exercício para o desenvolvimento do equilíbrio que sofre com os preconceitos. Para Guts Muths, a funambulação em si não é perigosa, mas sim, a sua execução como arte. Conforme aponta Soares (200 I), os acrobatas utilizavam o controle que tinham sobre seus corpos de forma livre, colocando-se constantemente em posições arriscadas, invertendo a ordem das coisas. Seu mundo, portanto, cheio de espontaneidade, desafiava o esquadrinhamento proposto pela sociedade do século XVIII, fazendo com que acrobatas fossem vistos como figuras marginais, que não se fixavam. Na ginástica, portanto, cortam-se os exageros e as inutilidades: a energia do corpo é gasta sempre de forma proveitosa, com alguma finalidade específica. Busca-se manter a alegria, mas nunca o exagero e a futilidade. Não se anda numa corda, não se escala uma árvore apenas pelo desafio de fazê-lo: anda-se sobre a corda e escala-se uma árvore sempre com segurança, para melhorar as capacidades e habilidades corporais, para formar cidadãos saudáveis, fortes, corajosos.

Grande atenção é dada ao banhar-se e ao nadar, que permitem ao corpo livrar-se dos humores aprisionados sob as roupas. $\bigcirc$ banho frio

reforça todos os músculos e todos os nervos; concede ao corpo a poderosa capacidade de suportar o frio; forja a pele na tensão ou frouxidão da qual muito depende contra a 
influência do ar e a deixa apta para o exercício de sua função natural, perspiração; refresca todo o sistema; dá ao corpo vigilância e animação dos espíritos; e é particularmente útil para resfriar o sangue no calor do verão (GUTS MUTHS, I800, p.344).

Além dos benefícios trazidos pelo banhar-se e pelo nadar, estas atividades apresentam ainda uma importância social. Se alguém se encontra em perigo em algum rio ou lago, aquele que sabe nadar está apto a resgatá-lo. Portanto, indica-se às pessoas experientes no nado, que esporadicamente o pratique com roupas, preparando-se assim para uma situação de emergência.

Uma última observação com relação à sistematização proposta por Guts Muths diz respeito à utilização de exercícios militares. Pereira ([1 960?]) afirma que Guts Muths se posicionava contra a inserção dos exercícios militares na escola

\begin{abstract}
$1^{\circ}$ porque eles dariam à escola um caráter militar que muito prejudicaria o livre desenvolvimento do corpo e do espírito da juventude; $2^{\circ}$ porque a aprendizagem dos exercícios militares tornaria sombrio o temperamento naturalmente alegre dos jovens; $3^{\circ}$ porque $[\ldots]$ a escola teria consagrado vários anos para obter um resultado que se alcança no exército em tempo muito mais curto. $4^{\circ}$ Porque os exercícios militares são limitados e unilaterais e expõem por consequência os jovens a contrair bastante cedo a rigidez dos membros; eles têm necessidade de exercícios variados, que os desenvolvam harmonicamente, e não unilateralmente (PEREIRA, [1960?], p. 233).
\end{abstract}

Entretanto, em Ginástica para a Juventude, Guts Muths afirma que os exercícios militares podem ser vantajosos para ensinar aos jovens a "subordinação, sem a qual a sociedade é um caos" (GUTS MUTHS, I800, p. 334), estando convencido de que,

seria muito benéfico introduzi-los na supervisão diária da juventude; e que um estabelecimento militar bem conduzido é desejável nas escolas; (...) É um espetáculo agradável quando crianças e jovens voam para seu espaço à palavra de comando, se agrupam em ordem, assumem boa atitude, e marcham em um corpo regular para onde quer que você os dirija.

Em sua opinião, tomando-se o cuidado de não tratar o jovens como escravos, os exercícios militares constituem uma ótima maneira de animar a coragem da juventude, fortificando sua audácia natural, seu espírito aventureiro, e prevenindo-os da efeminação derivada dos modos de vida contemporâneos.

Além das regras particulares a cada exercício, Guts Muths estabelece algumas orientações mais gerais para a prática da ginástica. Os exercícios deveriam ser realizados logo de manhã, de forma a fatigar o corpo do aluno e deixá-lo mais inclinado aos estudos; as roupas deveriam ser apropriadas para a prática dos exercícios, que deveriam ser sempre iniciados pelos mais leves, nunca pelos mais violentos; nunca se deve tornar o corpo do jovem insensível ou exauri-lo; o professor deve sempre 
estar atento ao correto posicionamento do corpo durante a execução dos exercícios; é necessário manter sempre um determinado grau de regularidade militar e obediência; os alunos fracos devem ser distinguidos dos saudáveis, e nunca avaliados pelos mesmos padrões, conhecendo a constituição de seus alunos; priorizar o exercício das partes mais enfraquecidas do corpo do aluno; e o ginasta deve sempre ter em mente o nível de seus alunos para que não passe exercícios acima de suas habilidades e, assim, evite o perigo.

Pode-se perceber, portanto, que o trabalho desenvolvido por Guts Muths neste início da sistematização dos exercícios físicos, era impulsionado pela busca da formação, através da educação do corpo, de indivíduos espiritual e fisicamente completos, preocupando-se sempre com o desenvolvimento da saúde e das capacidades físicas a partir de princípios médicos e higienistas, e sempre em conjunto com o desenvolvimento intelectual. Essa tentativa era permeada não apenas pela preocupação em formar jovens fortes e saudáveis, mas também em garantir que houvesse alegria e prazer na prática dos exercícios. Afinal, a ginástica, para Guts Muths, nada mais era do que "o trabalho na forma de alegria juvenil".

"Labor in the garb of youthful mirth": gymnastics according to Johann Christoph Friedrich Guts Muths

ABSTRACT: This paper focuses on the work of Johann Christoph Friedrich Guts Muths. At the end of the $18^{\text {th }}$ Century, this German teacher published one of the fundamental works for German gymnastics: Gymnastik für die Jugend (Gymnastics for Youth). Based essentially on the theories of the medical police, it presents a strong defense of the introduction of physical exercises as important means of regenerating and strengthen the German population.

KEYWORDS: History of gymnastics; Germany; Guts Muths; education of the body.

"El trabajo como alegría juvenil”: la gimnasia según Johann Christoph Friedrich Guts Muths

RESUMEN: Este trabajo tiene como propósito analizar la obra de Johann Christoph Friedrich Guts Muths, pedagogo alemán que en el fin del siglo 18 publicó una de las obras fundamentales de la gimnasia alemana: Gymnastik für die Jugend (Gimnasia para la Juventud). Su trabajo se basa especialmente en las teorías de la policía médica y defiende vigorosamente la introducción de los ejercicios físicos como instrumento de regeneración y fortalecimiento de la población alemana.

PALABRAS CLAVES: Historia de la gimnasia; Alemania; Guts Muths; educación del cuerpo. 
DONZELOT, J. A polícia das famílias. Rio de Janeiro: Graal, 1986.

FOUCAULT, M. Segurança, território e população. São Paulo: Martins Fontes, 2008.

GUTS MUTHS, J. C. F. ( I793) Gymnastics for youth. Philadephia: P. Byrne, 1800.

LEONARD, F. E. A guide to the history of Physical Education. $2^{\text {nd }}$ ed. Philadelphia: Lea \& Febiger, 1927

PEREIRA, C. F. M. Tratado de Educação Física: problema pedagógico e histórico. Lisboa: Bertrand, [1960?]. v.I.

ROSEN, G. Da polícia médica à medicina social. Rio de Janeiro: Graal, 1980.

ROUSSEAU, J. J. Emílio, ou, da educação. São Paulo: Divisão Européia do Livro, 1968.

SOARES, C. L. Acrobacias e acrobatas: anotações para um estudo do corpo. In: BRUHNS, H. T.; GUTIERREZ, G. L. (Org.). Representações do lúdico: II ciclo de debates lazer e motricidade. Campinas: Autores Associados, 2001

TESCHE, L. O turnen, a educação e a Educação Física nas escolas teuto-brasileiras no Rio Grande do Sul: I852- 1940. ljuí: Ed. da Unijuí, 2002.

THOMAS, K. O homem e o mundo natural: mudanças em relação a plantas e aos animais ( 1500- 1800). São Paulo: Companhia das Letras, 200 I.

WILLIAMSON, G. S. The longing for myth in Germany. Chicago: University of Chicago, 2004

Recebido: 24 nov. 2010 Aprovado: 28 fev. 2011

Endereço para correspondência:

Evelise Amgarten Quitzau

Rua Dom Idelfonso Stehle, 4I I, Cidade Nova Indaiatuba/SP

CEP: 13.334-180 